Citation: Morison, T., \& Herbert, S. (2018). Rethinking 'Risk' in Sexual and Reproductive Health Policy: the Value of the Reproductive Justice Framework. Sexuality Research and Social Policy, Online First, 1-12.

Available at: https://rdcu.be/bmfA8

Note: This is a pre-print version and may contain errors or omissions.

\title{
Rethinking 'risk' in sexual and reproductive health policy: The value of the sexual and reproductive justice framework
}

\begin{abstract}
Using the case of Sexual and Reproductive Health Strategy in Aotearoa (New Zealand), this article interrogates the dominant risk discourse in sexual and reproductive health policy. It highlights the tensions between risk discourse and broader equity goals, which are increasingly seen as significant within sexual and reproductive health. Working within a post-structuralist perspective, discursive methodology is used to explore the positioning of youth in ten (10) policy documents. The analysis shows how the risk discourse, along with a developmental discourse, creates three common youth subject positions: youth as at risk and vulnerable; as not-yet-citizens; and as especially vulnerable relative to other young people. It demonstrates how these positions may be associated with 'new' or covert forms of morality and stigmatization. Detailing the implications for ethnic minorities in particular, it adds to prior analyses of gender- and class-based inequities. The Sexual and Reproductive Justice framework, which encompasses notions of rights and justice, is discussed as an alternative to risk-based policy development that can attend to sexual and reproductive health inequities.
\end{abstract}

Keywords: risk; sexual and reproductive health policy; youth; social inequities; sexual and reproductive justice

\section{Introduction}

The rise of a risk discourse in public health has been well documented (Lupton, 2013; Peterson \& Lupton, 2000). As a result of the increasing dominance of this way of framing health issues, health and social policy commonly focus on individual risk. In line with the prevailing problematisation of youth sexuality, Sexual and Reproductive Health policy frequently features young people as a specific at-risk group that requires special attention (Brown, 2016). This is exemplified in Aotearoa's (New Zealand) Sexual and Reproductive Health Strategy which aims to "maximis[e] the health of at-risk groups, such as Youth, Māori, and Pacific peoples" (Ministry of Health, 2001, p. iii). Of interest within this policy however, is the concurrent attempt to speak also to concerns regarding health inequalities, recognising that these cohere around marginalised social identities. This is reflected in the Strategy's overall vision of "Good sexual and reproductive health for all New Zealanders" (Ministry of Health, 2001, p. 3) and is related to the government's broader goal of "reducing health inequalities that exist between different population groups" (Ministry of Health, 2003, p. 14). This goal is related also to the State's commitment to Te Tiriti o Waitangi (the Treaty of Waitangi), which establishes a Māori-Crown partnership, to strive for equitable 
outcomes for all citizens (Green, Tipene, \& Davis, 2016). The right to good sexual and reproductive health for Māori is implicit under Te Tiriti and disparities are thus considered a violation of this founding document (Durie, 2003).

In this article, we call into question whether a risk-centred policy approach can truly fulfil the government's aspirations and duty of reducing sexual and reproductive health disparities among those it has prioritised-including young people, and its associated aim of countering the stigmatisation of particular youth (Ministry of Health, 2001). Using discursive methodology, within a post-structuralist theoretical framework, we interrogate the use of 'risk' as a dominant discursive resource in Aotearoa's sexual and reproductive health policy. We identify the common social identities, or positions, made available through talking about youth sexual and reproductive health in this way and the implications of these positions for sexual and reproductive health outcomes. Our analysis of the policy produced under the Sexual and Reproductive Health Strategy (2001) demonstrates how, instead of providing a framework that can draw attention to existing health and social inequalities between different social groups, current policy may in fact run the risk of entrenching these.

Our findings add to the evidence produced in other contexts - which also draws attention to the pitfalls of risk-centred youth policy (e.g., Brown, Shoveller, Chabot, \& LaMontagne, 2013; Macvarish, 2010; te Riele, 2006, 2015) — and provides a case to illustrate the tensions between risk discourse and health equity goals. Further, it highlights the implications for ethnic minorities in particular, adding to prior analyses that have centred around gender- and class-based inequities (Brown, 2016; Brown et al., 2013; Lupton, 2012; Macvarish, 2010). Aotearoa provides a distinctive and useful case for such an analysis, because of the obligations contained in Te Tiriti, which necessitate careful attention to disparity along ethnic lines (Green et al., 2016). We contribute to the scholarly discussion by proposing an alternative framework for policy development, that of Sexual and Reproductive Justice, which challenges the individualising tendencies of the risk discourse that currently dominates sexual and reproductive health policy.

\section{Background: The Sexual and Reproductive Health Strategy of Aotearoa}

Aotearoa's current Sexual and Reproductive Health Strategy (Phase one), launched almost two decades ago, in 2001, details the vision, guiding principles, and strategic direction of sexual and reproductive health for the country (Ministry of Health, 2001). It is important to note that the formulation of the Strategy coincided with the rise of neoliberalism in public health within Aotearoa and farther afield. Gaining traction in the 1980s, neoliberal ideology has become a powerful public discourse shaping public policy-making in late capitalist societies. This pervasive discourse promotes "the expansion of an economic rationality to all domains of social life ... [and] ... encourages a particular kind of individual entrepreneurial enterprise whereby what were previously deemed to be the state's responsibilities have been devolved to responsible, rational individuals" (Horrocks \& Johnson, 2014, p. 175). The emphasis on market freedom and reduced 
government intervention is ostensibly in the interests of free choice, personal freedom, and relief from the 'nanny state' (McGregor, 2001).

In Aotearoa, growing neoliberalism led to a process of health reform that ultimately reduced public funding (e.g. of District Health Boards) and regulation of health services, resulting in greater privatisation of healthcare (Ware, Breheny, \& Forster, 2016). During this time, public sexual and reproductive health specialist services have been compromised and to a large extent delegated to primary health care provider creating wide variations in availability, quality, and access to services (New Zealand Sexual Health Society, 2011). Overall, the state has demonstrated a lack of strategic and coordinated action for improving youth sexual and reproductive health (New Zealand Sexual Health Society, 2011; Women's Health Action, n.d.). As we explain more fully below, in the context of diminished state support of healthcare and the privatisation of care, individuals are increasingly positioned as consumer-citizens responsible (and potentially to blame) for their own sexual and reproductive wellbeing (Prince, Kearns, \& Craig, 2006). The influence of neoliberal ideology is, therefore, apparent in the policy that we review and can explain the dominance of risk discourse.

Under the Sexual and Reproductive Health Strategy, there have been gains in some areas of youth sexual and reproductive health. For instance, the teenage pregnancy rate has halved in the last decade (Family Planning New Zealand, 2017). ${ }^{i}$ Nonetheless, the country still performs poorly relative to other 'similar' countries in the OECD, with high a high teenage pregnancy rate and disproportionately higher sexually transmitted infection rates among 15-24 year-olds than other age groups (Clark et al., 2016; Social Policy and Evaluation Research Unit [SUPERU], 2015). Notably, two decades after the inception of the Sexual and Reproductive Health Strategy the evidence shows that disparities among youth persist. Any overall improvements in sexual and reproductive health have generally not translated into significant gains for the very young people prioritised in the Sexual and Reproductive Health Strategy. Instead, those who are socioeconomically deprived and/or from ethnic minority groups continue to bear the greater burden of poor sexual and reproductive health (Clark et al., 2016; Clark, Crengle, Sheridan, Rowe, \& Robinson, 2014; Redstone \& Conn, 2011).

There has been growing recognition of persistent health disparities in Aotearoa, including in the area of sexual and reproductive health (Miller, 2016). Yet, despite being highlighted in the Strategy, the sexual and reproductive health of marginalised groups has been neglected in policy and programming (Clark et al., 2016; Green, 2011). As Clark and colleagues point out "to date, no updated national strategy in relation to sexual health in NZ has been launched. Furthermore, over the past decade there appears to have been a general lack of development of resources for and commitment to sexual and reproductive health. Urgent attention is required to reprioritise the sexual and reproductive health of youth, and to ensure that all young people have the education, resources and services they require" (Clark et al., 2016, p. 335). 
Amid growing calls for strategic direction in the sexual and reproductive health sector for (e.g., Family Planning New Zealand, 2017; New Zealand Sexual Health Society, 2011; Women's Health Action, n.d.) and for the liberalisation of Aotearoa's out-dated abortion law (McCulloch \& Weatherall, 2017), and given the evidence of continued sexual and reproductive health disparities, the time is ripe for attention to be given to updating the sexual and reproductive health policy. Part of this endeavour, we maintain, will involve rethinking the emphasis on risk in sexual and reproductive health policy. Sustained action towards dismantling entrenched sexual and reproductive health inequities among youth will require policy that moves beyond an ineffective neoliberal "model of individualised risk and responsibility" (Terry, Braun, \& Farvid, 2012, p. 318). As we explain in the following section, which outlines our poststructuralist understanding of risk, the insistent focus on the individual within neoliberal risk discourse obscures the social, systemic, and structural issues underpinning youth sexual and reproductive health disparities (Terry et al., 2012).

\section{Methodology}

This analysis of policy forms part of a larger project concerning public discourses of youth sexual and reproductive health in Aotearoa. In this article, we home in on the deployment of risk as a dominant discourse in sexual and reproductive health policy. Taking a post-structuralist view of risk, we reject the common view that discussions of youth-at-risk simply describe "real" dangers faced by young people. Instead, we argue that the naming of specific risks in youth sexual and reproductive health policy is not a morally or ideologically neutral exercise. Rather, risk is seen as socially constructed toward particular ends (Lupton, 2013). Singling out particular hazards over others involves a process of interpretation or selection. This process is informed by culturally defined moral problems, power relations, ideas about proper development, ideal citizenship, and, invariably, what is in the state's interests (Brown et al., 2013). Risks are, therefore, "always political in their construction, use and effects, and inevitably include moral judgements" (Peterson \& Lupton, 2000, p. 13), although these dimensions are frequently obscured by epidemiological and other 'objective' evidence.

The formulation of individualised risk in turn forms part of a range of technologies of regulation marshalled toward the re/production of the responsible, rational, autonomous, and choice-making consumer-citizen (Lupton, 2013). Ever-diminishing government support and 'freedom' from direct government control within neoliberal contexts comes at a cost. Individual citizens must manage their own health risks, shouldering the responsibility of any negative outcomes. The ideal social subject is, therefore, a prudent risk manager who accepts responsibility for personal wellbeing and refrains from harming others through their choices (Kelly, 2001; Terry et al., 2012). Thus, rather than direct intervention, the primary mode of governance involves motivating individual consumer-citizens to make healthy choices and to regulate their practices for their own sake and for the greater good (Prince et al., 2006). When it comes to youth sexual and reproductive health, this translates as a focus largely on modifying young people's sexual risk behaviours and 
lifestyle 'choices' (Shoveller \& Johnson, 2006). The neoliberal state's primary role is thus not governance of risk on behalf of its citizens, but governance by risk (Rothstein, 2006). In this mode of governance, risk exposes (certain) youth to surveillance and expert intervention, promoting selfregulation in order to control undesirable, 'risky' behaviours or situations (Macvarish, 2010; Monterro \& Kelly, 2016).

\section{Data collection}

The policies selected for analysis were located using a systematic online search of academic databases and relevant websites (e.g., District Health Boards, Ministry of Health). We identified 10 relevant policy documents for analysis on the basis that they: focus on sexual and reproductive health; make substantive mention of youth; and are specific to Aotearoa. Given our interest in the current national Sexual and Reproductive Health Strategy, we only analysed policies published from 2001 to onward. (See summary in table 1 below.) The earliest policies (5) produced between 2001 and 2003 form part of the Labour-led reform of sexual and reproductive health policy. These largely set the tone for those produced subsequently (5), largely at the regional level, which derive from and extensively cite the foundational policy statements.

Table 1. Data set: Policy documents from 2001

\begin{tabular}{|c|c|c|c|}
\hline Author & & Title & Type \\
\hline Ministry of Health & 2001 & $\begin{array}{l}\text { Sexual and Reproductive Health Strategy } \\
\text { (Phase 1) }\end{array}$ & Policy \\
\hline Ministry of Youth Affairs. & 2002 & Youth Development Strategy Aotearoa & Policy \\
\hline Ministry of Health & 2002 & Youth Health - A guide to action. & Action plan \\
\hline Ministry of Health & 2003 & $\begin{array}{l}\text { HIV /AIDS action plan (Phase two of the } \\
\text { Sexual and Reproductive Health Strategy) }\end{array}$ & Action plan \\
\hline Ministry of Health & 2003 & $\begin{array}{l}\text { Sexual and Reproductive Health, resource } \\
\text { book(Phase 2) }\end{array}$ & Action plan \\
\hline Tairawhiti District Health & 2008 & Sexual Health over Tairawhiti Strategy & \\
\hline $\begin{array}{l}\text { West Coast District Health } \\
\text { Board }\end{array}$ & 2009 & Youth/Rangatahi Plan & Action plan \\
\hline $\begin{array}{ll}\text { YouthLine } & \text { Auckland } \\
\text { Charitable Trust } & \end{array}$ & 2011 & Youth Sexual and Reproductive Health & $\begin{array}{l}\text { Position } \\
\text { statement }\end{array}$ \\
\hline $\begin{array}{l}\text { Taranaki District Health } \\
\text { Board et al. }\end{array}$ & 2013 & Taranaki Taiohi Health Strategy $2013-2016$ & Action plan \\
\hline
\end{tabular}

\section{Data analysis}

In order to analyse the positioning of youth in sexual and reproductive health policy, our analytical approach is drawn from discursive psychology. Based on the premise that talk is constitutive, we consider certain renditions of an event, person, or experience as discursively produced as people draw on particular shared sets of meanings known as discursive resources (Reynolds, Wetherell, \& Taylor, 2007). This approach connects the wider notion of discursive resources (e.g., risk discourse) to particular positions in talk (e.g. "at-risk" youth) as well as the power relations implicated within these (e.g. expert/adult intervention) (Reynolds et al., 2007). 
To explore the positioning of youth in sexual and reproductive health policy documents, we began with a process of identifying commonly drawn on discourses. This involved thematic coding across the dataset for patterns of language use indicated by recurring words, metaphors, ideas and imagery. For example, common references to "developmental changes", "teenage years", "transition", and "stages" cluster around a particular understanding of youth that draws on developmental psychology. Each of these initial coded themes was then further analysed to construct defined discourses. Hence, to continue with the previous example, a developmental discourse was identified. We then examined the ways that each of these discourses, possibly in conjunction with others, work to position youth (e.g., as in transition), how these positions relate to other subjectivities (e.g., parents), and the wider implications of being positioned in this way (Morison \& Macleod, 2015).

\section{Findings}

Our analysis concentrates on risk as the dominant discursive resource within sexual and reproductive health policy. As we shall show, risk was strongly reinforced by a developmental discourse. Together, these discourses are drawn on within sexual and reproductive health policy to produce three common positions for youth, viz., 'youth as risk'; 'youth as citizens to be'; and, 'the most vulnerable' youth. We outline each of these positions in turn, drawing on exemplary quotes from the data to illustrate each. The quotes are produced verbatim, but we have used bold font to draw attention to significant words or phrases.

\section{Youth as risk}

In comparison to the general population, youth are positioned as being particularly at risk or vulnerable in relation to sexual and reproductive health, with young age itself construed as a risk factor. This is achieved through the deployment of the developmental discourse; an influential and powerful expert discourse which constructs adolescence as a time of transition to adulthood, inevitably involving turmoil, rebellion, or "storm and stress" (Macleod, 2017). According to Montero and Kelly (2016) positioning of young people within this discourse draws on "understandings of young people as risk takers, as well as young people at risk due to inherent characteristics - their inexperience, biological factors, lifestyle and peers" (p. 53). Within sexual and reproductive health policy a developmental discourse thus intersects with, and reinforces, a risk discourse, as illustrated below.

Quote 1: Most young people are healthy most of the time... But the years between 12 and 24 are also the years when the chances of being caught up in risk-taking behaviour are high, and where the negative consequences can be lifelong [sic]. While most young people appear to deal successfully with the developmental changes that occur during this period, there is evidence that many do not. Compared with other age groups, young people have: • high rates of mental illness • high rates of alcohol and drug use and abuse, particularly among young men $\cdot$ a higher rate of suicide and suicide attempts $\bullet$ high rates of sexually transmitted infections. Morbidity and mortality 
data show that young New Zealanders have higher rates of suicide, teenage pregnancy, abortion and suffer more injuries - especially from traffic accidents - than their counterparts in other OECD countries (Ministry of Health, 2002).

In this quote, the accumulation of factors associated with risk serves to move the apparently healthy teenage body into the sphere of danger, positioning youth as at risk. Such positioning is reinforced by "quantification rhetoric" (Peterson \& Lupton, 2000, p. 23), the deployment of statistical evidence for the categorisation of risk. This rhetorical device was common in the documents analysed, which relied strongly on the expert discourse of epidemiology to construct categories of youth risk. This mobilisation of expert and scientific discourses, as Lupton (2013) has also shown, establishes the notion of at risk youth as an objective, 'value free' fact that is difficult to challenge.

The operation of the developmental discourse is apparent in reference to "developmental changes" that are seen as making young people more inclined to "risk taking behaviours" and, consequently, poor health outcomes. The positioning of young people as risky/at risk is a relatively more recent construction of youth, but also connects with long-standing assumptions of young people as feckless: rebellious, overestimating their invulnerability to harm, susceptible to peer influence, and ignorant about, or unconcerned for, the effects of health damaging behaviours on themselves and others (Monterro \& Kelly, 2016). The developmental discourse can therefore reinforce a deficit view of young people as unreliable or lacking concern for their own and others' best interests (Brown et al., 2013; Monterro \& Kelly, 2016). Indeed, commentators have argued that a discourse of risk, in which vulnerability is associated with intrinsic predisposition, potentially positions teenagers as blameworthy; responsible for harm resulting from poor choices or bad behaviour and perhaps even inviting a range of risks (Gorur, 2015; Kelly, 2001).

However, in the policy we analysed, overall, care is taken to avoid blaming youth. The developmental discourse is drawn on instead to position youngsters in ways that render them not accountable for actions that lead to poor sexual and reproductive health outcomes: as potentially under threat, "at risk", and as "vulnerable to external risk factors". The quote below illustrates how the developmental discourse is mobilised to avoid overt moral judgement of youth and position them as vulnerable instead.

Quote 2: It is important to design policies and programmes that both build young people's capacity to resist risk factors and enhance the protective factors. For example, some young people experience difficulty at some or all stages of their development (and are frequently referred to as 'at risk'). They can have a range of 'youth problems', such as offending behaviour, truancy, unsafe sexual behaviour, self-harm, and drug abuse. Additional help for these young people needs to be consistent with the youth development approach - that is, it needs to avoid defining the young person as 'the problem' (Ministry of Health, 2002).

Here the construction of youth as risk-takers is reinforced by describing certain risky activities (e.g., unsafe sex, drug use) as "youth problems". These "problems" are, of course, not exclusive 
to young people, but drawing on the developmental storm-and-stress trope allows them to be seen as such. Contextual dynamics are reduced to risk or protective factors that impact on individual action. However, these risky behaviours are ascribed to developmental "difficulty" or "problems" that young people "have" (as opposed to what they $d o$ ), with the ultimate aim being to "avoid defining the young person as 'the problem'". Instead, youth are positioned as (potential) victims of forces beyond their control.

The contravention of (white, middle-class) developmental norms, rather than moral ones, are presented as related to "risk factors or negative outcomes with which 'at-risk youth' are correlated via statistical models" (te Riele, 2015, p. 25). The language of developmental psychology thus replaces moral rhetoric as those problematic aspects of youth sex and reproduction (behaviours, living conditions, choices, attitudes, or values) once described as morally inappropriate are now articulated as developmentally problematic (Brown, 2016; Brown et al., 2013; Ware et al., 2016). Risky behaviours are now open to adult intervention and, when articulated in developmental terms (rather than in terms of 'right or wrong'), intervention takes on a particular form (Kelly, 2001). Based on the assumption that youth are not fully equipped for the future, as we explain in the following section, intervention becomes about adult experts equipping youth to "resist risk factors and enhance the protective factors" (quote 2) to build individual resilience to risk.

\section{Youth as citizens-to-be}

The developmental understanding of youth as a transitional stage intersects with risk discourse descriptions of potential negative consequences for youth sexual and reproductive health. Together, these discourses construct a "threat of degeneration" (Macleod, 2017, p. 173): the association of individual development with the development of broader society. This threat "accounts for the construction of the risky teenager who is constantly a potential threat to her own well-being but also to the body politic (society as a whole)" (p. 173). For instance, the Youth Health Action Plan states: "On the basis that healthy young people become healthy adults, it is in the community's interest to focus on keeping young people well, and to find more effective ways of doing this" (Ministry of Health, 2002, p. 7). Young people are therefore rendered as being in a process of transition toward 'healthy', normative adulthood. In addition, the reference to the "community's interest" alerts us to the underlying positioning of young people as not just future adults, but future citizens. The process of transition suspends youth in a state of not-yet citizens. Accordingly, a distinct subjectivity is constructed for youth as citizens-to-be (Kelly, 2001).

The emphasis then is on mitigating negative consequences among youth and equipping them with relevant skills to ensure they transition to full 'healthy' adult members of society, as further illustrated below.

Quote 3: The Strategy is about how government and society can support young people to develop the skills and attitudes they need to take part positively in society now and in the future (Ministry of Health, 2002). 
Quote 4: Increase individual's understanding and personal skills and teach them to value themselves (personal identity and self-worth) by ensuring appropriate health education is provided for everyone, which aims to increase healthy sexual and reproductive health choices. The skills to practice safe sex and a guide to provide families with skills to support and advise their children regarding aspects that may affect their sexual behaviour can pave the way to a sexually healthy younger generation (Youthline Auckland Charitable Trust, 2011).

In these quotes, young people are explicitly positioned as citizens-to-be: the "younger generation" (quote 4) that must be equipped for positive societal participation "now and in the future" (quote 3 ). Youth are construed as lacking agency prior to adult/state intervention and as still needing to acquire the attributes ("personal skills", "attitudes", "knowledge" and "understanding") necessary to "resist risk factors" (Macvarish, 2010). The implicit threat evident in quote 3 in particular, is that young people's development as valued citizens may be interrupted (Breheny \& Stephens, 2010). Youth are, therefore, seen as requiring adult "support" or assistance, without which they may fail to develop the attributes and capabilities required to mitigate or manage risk and thus become a threat to future societal wellbeing (Monterro \& Kelly, 2016). As the quotes above show, the developmental scaffolding of risk discourse emphasises universal developmental tasks, processes, and attributes that sexual and reproductive health policy often refers to as "skills" yet to be acquired by youth.

The scaffolding of risk discourse in developmental terms supports an individualised conception of youth risk that coheres with a neoliberal logic (Brown et al., 2013). While environmental dynamics (e.g., socio-economic status, family background) are certainly acknowledged in sexual and reproductive health policy, these are rendered as risk or protective variables to be negotiated by the individual young person. Both the risks (e.g., adverse family situation) and the site of intervention (e.g., empowerment, building skills or resilience) are located at the individual level (te Riele, 2006) and youth are positioned as "responsible for future life chances, choices and options within institutionally structured risk environments" (Kelly, 2001, p. 30). In effect, reasons for poor sexual and reproductive health are still displaced onto individuals and socio-structural factors remain in the background. Despite recognition of environmental factors, individual young people are tasked with the responsibility for effectively self-managing risks, such as avoiding STIs or unwanted pregnancy by practicing safer sex or delaying sexual debut. Little attention is given to contextual issues beyond their ability to access services. This positioning of youth is based on an "unarticulated and unrealistic set of assumptions about the level of agency and control that is afforded to many young people" (Shoveller \& Johnson, 2006, p. 47), especially for socially marginalised young people, who may have fewer choices and less agency to exercise these than those in privileged social positions.

This individualised construction of youth risk prompts specific kinds of intervention that will allow young people to increase their capacities to identify and avoid risks ("make safe choices"); to develop the ability to withstand the risk ("resist risk factors", "practice safe sex", "take part 
positively in society"); or, to be resilient and overcome the exposure to risk. Following neoliberal logic, in order to equip youth as ideal self-regulating citizens-to-be who are able to mitigate risk, "programs, interventions, and practices need to be developed and deployed to encourage the young self to imagine itself as an enterprise, as being, potentially, autonomous, choice making, prudent, risk aware, and responsible" (Monterro \& Kelly, 2016, p. 55). Accordingly, within the sexual and reproductive health policy interventions are predominantly envisaged as equipping responsible self-management in relation to sex, as exemplified by the excerpt below.

Quote 5: Our young people know when they need help; we need to encourage people to be aware of their bodies, aware when things are not right, aware when they have taken risks that may lead to problems in the days, weeks or years ahead (Tairawhiti District Health, 2008, p. 35).

In this extract, emphasis is placed on self-surveillance (being "aware") and self-regulation (anticipating future problems, seeking "help") and so the young person is positioned as primarily responsible for their own wellbeing and for timely help-seeking. This quote also illustrates how intervention into young people's sexuality and reproduction is commonly represented as acting in young people's best interests: as "helping" or "supporting" youth, towards successful transition into responsible, healthy adulthood.

This construction of a need for help or support from more knowledgeable adults forms part of what Macvarish (2010, p. 316) refers to as a "therapeutic tendency" in youth sexual and reproductive health policy. The quotes above show how intervention is strongly linked to psychosocial factors as the emotional, psychological, and communication competences of young people (and sometimes of their parents/families) are singled out as needing improvement. With few exceptions, almost no attention is given to addressing the ways in which social environments and structures contribute to vulnerabilities and/or constrain the choices available to young people (Terry et al., 2012). The concern with emphasising personal risk factors over contextual factors for so-called vulnerable young people is that it may contribute to moral panic regarding the threats they pose to others (e.g., their infants or society), as well as victim blaming (te Riele, 2015).

\section{"The most vulnerable"}

The mobilisation of a developmental discourse renders all young people as potentially risky and/or vulnerable to risk, providing the rationale for the surveillance and intervention to prevent possible risk (Kelly, 2001). However, as te Riel (2015, p. 17) points out, "in much research, policy, and service provision, certain young people are identified as being more in need of support, more at risk, or more vulnerable than others of the same age". This is evident in our data. While young people in general are positioned as at risk due to their developmental stage, particular groups of young people are singled out as requiring special attention. For example, by virtue of ethnicity, disability status, social deprivation, and migrant status, certain youth are positioned as "most vulnerable" or "most at risk". The further differentiation among youthful populations is alluded to 
in quotes 1 and 2 above, where qualifiers ("most", "some", and "many") are applied to constructions of risk in order to position particular young people in this way.

Young people are also categorised in terms of their vulnerability in relation to others of the same age (te Riele, 2015). In Aotearoa sexual and reproductive health policy, this is done largely along ethnic lines (Ware et al., 2016). For instance, the Sexual and Reproductive Health Resource book states that: "Among young New Zealanders, and rangatahi Māori [Māori youth] particularly, unplanned pregnancies, abortion and sexually transmitted infections are becoming more common - with potential long-term consequences for their health and their fertility" (Ministry of Health, 2003 , p. v). Likewise, references to the statistical likelihood of experiencing undesirable sexual and reproductive health outcomes or proportional comparisons between ethnic groups, establishes and justifies, the argument that ethnic minority youth require special attention in sexual and reproductive health policy and interventions. As mentioned above, an epidemiological discourse validates the singling out of particular groups of youth (e.g., along ethnic lines) as being most vulnerable or more vulnerable in comparison to other youth. This is illustrated in the quote below.

Quote 6: Overall, young people are less likely to be parents than in the past. By the age of 25 most women (63.2 percent) have not had children. However, Māori women in their late teens and early 20 s have higher rates of pregnancy than other women of the same age. Birth rates for young Māori women under 18 years in 2000 were 22.7 births per 1,000 compared with 4.9 per 1,000 for nonMāori young women (Ministry of Youth Affairs, 2002, p. 43).

In the example above, "quantification rhetoric" (Peterson \& Lupton, 2000, p. 23) distinguishes between a normative category (young people overall) and a deviant category (young Māori women). The construction of these categories provides a basis for comparison, seen throughout our data, in which statistics function as "a technology for defining norms and deviations from the norm" (Peterson \& Lupton, 2000, p. 23). Similar to Green's (2011, p. 30) findings, we noted the continual unfavourable comparison between Māori and 'everyone else', as well as the repeated positioning of Māori and Pasifika as the Other. This process of constructing normative mainstream versus deviant minority categories through quantification rhetoric can be criticised as amounting to statistical dehumanisation or stigmatisation (Macvarish, 2010).

Such logic allows for the construction of groups of young people as 'most vulnerable', by identifying and quantifying a range of risk factors that serve to position certain young people as at risk in particular circumstances (Monterro \& Kelly, 2016). This is illustrated in the following excerpts.

Quote 7: Young people who use these services most, tend to be those who are most vulnerable those from lower socioeconomic settings, those who have chronic health problems, those with the highest health risk behaviours (eg, unprotected sex, drink driving) (Ministry of Health, 2002, p. 17). 
Quote 8: Recent New Zealand research supports the international findings. In the Christchurch Child Development Study young women who became pregnant were more likely to be Māori, to have experienced an adverse family background, and to have done less well at school (Woodward et al 2001). Another longitudinal study found that, while many children to teenage mothers did well, as a group these children were more likely to have left school early, to have been long-term unemployed, to have engaged in violent offending and to have been young parents themselves (Jaffee et al 2001) ... (Ministry of Health, 2001, p. 1).

As demonstrated in these quotes, the identification of at-risk young people — and their subsequent positioning as "most vulnerable"-draws on "inventories of "risk and protective factors" (Monterro \& Kelly, 2016, p. 53). In the second excerpt, included among the listed risk factors (e.g., "adverse family background", poor scholastic performance) Māori ethnicity is included in such a way that ethnicity itself can be construed as a risk factor. The language of vulnerability may, however, provide the additional "guise of social concern ... based on a link with youthful age, which obscures the racial focus" (Breheny \& Stephens, 2010, p. 317).

In this way, despite positive intentions (of neutrality or benevolence), ethnicity and risk become conflated. In attempting to delineate risk factors, the focus is on young people's characteristics, but in this instance, the characteristics belong to an entire group, which is associated with negative images of dysfunction. Risk is thus inadvertently construed as related to group identity rather than the social environment (te Riele, 2006).

Such a construction oversimplifies the complex relationships between a range of individual, interpersonal and structural factors that together shape sexual and reproductive health outcomes. Instead, 'at-risk' or 'vulnerable' youth from ethnic minority groups, who live in conditions of inequity, are implicitly positioned as being at odds with society (Brown et al., 2013). Thus, for those from indigenous and other ethnic minority groups, risk rhetoric does not substantively differ in its effect from an overt deficit approach and it "is not much less stigmatizing or normative than labeling [sic] some young people 'problems', 'hoodlums', or 'delinquents'” (te Riele, 2015, p. 23).

\section{Discussion}

We have identified several pitfalls in Aotearoa's sexual and reproductive health policy that stem from the reliance on individualised, neoliberal risk discourse. Risk rhetoric-bolstered by a developmental discourse-works to position young people as at the mercy of risk-factors, in categorisations of youth vulnerability relative to peers, and in judgements regarding the ability to transition successfully into normative adulthood. Moreover, the individualising tendency of these discourses meant that risk is seen "either as an individual attribute or as a condition of particular groups of young people" (te Riele, 2006, p. 136). 
Of course, characterising young people in these ways is not without positive intention. The sexual and reproductive health policy asserts that a focus on risk allows appropriate services to be made available to those who require them most (te Riele, 2015). Also, the language of risk and resilience may, as te Riel (2015) has pointed out, "in some ways, relieve young [people] of responsibility for factors that might be beyond their control" (p. 23). Indeed, we noted how expressions of blame, moralising, and stigmatising were for the most part actively avoided in the policy.

The avoidance of blaming and stigmatising language also aligns with incorporation of a "strengthbased approach to child development" (Edwards, Mumford, \& Serra-Roldan, 2007, p. 29) in Aotearoa's sexual and reproductive health policy, known as the "Positive youth development approach". This approach, alluded to earlier and explained in the Youth health Action Plan (Ministry of Health, 2002, p. 21), involves "applying a consistent strengths-based approach to young people's health and wellbeing, which addresses both risk and protective factors, as well as developing the range of skills they need". While the intention may be to foreground youth resilience and other positive attributes, this objective, as we have shown, is undermined by the intersection of risk and developmental discourses.

Furthermore, the move away from moral to risk rhetoric may also be related to the awareness of "the lack of legitimacy, and potentially alienating effect, of 'old-fashioned' moralising" (Macvarish, 2010, p. 320), as noted in other contexts such as the UK (Brown, 2016; Macvarish, 2010) and Australia (Gorur, 2015). In Aotearoa, a further motivation might be to avoid a deficit view in social and health policy that has been criticised in previous years. For instance, Labour's "Closing the Gaps" policy approach, articulated in the late 1990s (just prior to the Sexual and Reproductive Health Strategy's inception) was condemned for "using non-Māori as the benchmark" and thus promoting "a deficit model of Māori development" (Durie, 2003, p. 160) and even "social apartheid" (New Zealand First, 2000).

While there may be benefits to framing youth sexual and reproductive health in terms of risk, our analysis indicates that the language of risk and vulnerability may not be effective in addressing some of the negative outcomes that policy-makers seek to avoid. The intersection of risk and developmental discourses may actually produce new or veiled" forms of morality and, by downplaying broader contextual factors, allow for covert stigmatisation and re-entrench the marginalisation of minority groups.

Considering these limitations, a revision of the almost two-decade old sexual and reproductive health policy framework is needed. Rather than articulating youth sexual and reproductive health policy in terms of individualised risk and responsibility, we suggest an alternative policy vision guided by a Sexual and Reproductive Justice framework.

\section{What is a Sexual and Reproductive Justice framework?}


The notion of reproductive justice, as it was originally termed, was developed in the 1990s by women of colour activists in the United States (e.g., Asian Communities for Reproductive Justice, 2005; Sistersong Women of Color Reproductive Health Collective and the Pro-Choice Public Education Project, 2007) and has its roots in critical and Black feminisms (Ross, 2018). This concept has increasingly been taken up and developed as a framework for sexual and reproductive health advocacy and programming, becoming somewhat of a 'buzzword' in the sector (Ross \& Solinger, 2017). The attractiveness of this framework lies in its explicit recognition of the ways that sexual and reproductive autonomy - the ability to exercise one's rights in these areas - are constrained by inequalities rooted in individuals' social positioning (e.g., age, class, race/ethnicity, gender).

Two key components underpin the Sexual and Reproductive Justice framework, namely, the notion of human rights and that of intersectionality. These components enable a two-pronged approach to policy-making that incorporates both rights and justice. The first, rights-based prong emphasises the entitlement to sexual freedom, bodily self-determination, and reproductive autonomy_rights traditionally emphasised within liberal feminism. The second, justice-based prong involves moving beyond the individual by foregrounding conditions that may obstruct the realisation of these rights. The Sexual and Reproductive Justice framework is therefore "based in [both] the human right to make personal decisions about one's life, and the obligation of government and society to ensure that the conditions are suitable for implementing one's decisions" (Ross, 2017, Reproductive Justice Flowers section, para. 9). It is this dual perspective that holds promise for addressing the shortcomings of the current sexual and reproductive health policy framework we have highlighted in this article. In what remains, we consider how this twopronged approach could strengthen Aotearoa's sexual and reproductive health policy.

\section{The first prong: a rights-based perspective}

The Sexual and Reproductive Justice framework draws directly on three interconnected global human rights, namely: (1) to refrain from reproduction by means of safe birth control, abortion, or abstinence; (2) to reproduce under conditions of one's choosing; and (3) to raise children in safe and healthy environments (Ross, 2017). Drawing on a Sexual and Reproductive Justice framework to reframe Aotearoa's sexual and reproductive health policy would explicitly introduce a muchneeded rights-based perspective - a development called for by scholars and others involved in the sector (e.g., Family Planning New Zealand, 2017; Green, 2011; Redstone \& Conn, 2011).

The language of human rights would allow youth to make stronger, more positive claims than policy currently allows. Articulating access to services, information, support, and care as entitlement - rather than risk mitigation - places a greater obligation on the state to ensure the necessary conditions for the realization of young people's rights. The current rather paternalistic role of the state can then transform from the protection of vulnerable youth to one in which the state is answerable to young people as empowered rights bearers. 
Significantly, the Sexual and Reproductive Justice framework goes beyond affirming the right to prevent unwanted pregnancy and emphasises the right to have children under the conditions of one's choosing (Ross, 2017). The current problematisation of early pregnancy in Aotearoa (and elsewhere) is based on the assumption that all teenage pregnancy is inherently problematic, failing to distinguish unwanted/unplanned from intended/wanted pregnancies and so at odds with an indigenous perspective of childbearing (Pihama, 2011). Instead, as we have shown, young indigenous women are pathologized and teenage pregnancy continues to be seen "as an indigenous issue or a "Māori problem"' (Ware, 2014, p. 3). Such negative constructions reiterate colonialist and eugenicist approaches to indigenous women's fertility. Recognising the longstanding propensity to spotlight and seek to regulate indigenous and minority women's fertility, the Sexual and Reproductive Justice framework upholds the right to have children and to raise them (Ross, 2017). Rather than casting 'early' motherhood as a transgression of the desirable (western, neoliberal) life trajectory, and thus necessarily problematic, articulating this right explicitly again shifts the focus onto the state and its responsibility to provide adequate conditions to support young mothers.

Closer aligningment of the Sexual and Reproductive Health Strategy with a rights-based perspective is only part of the solution, however. Feminist researchers have pointed to the propensity for rights-based approaches to be co-opted into the neoliberal agenda as individuals are expected to responsibly claim their sexual and reproductive health rights as autonomous choicemaking citizens (Lowe, 2016). This would simply reinforce the individualising tendencies of current policy. It is therefore important, as Macleod (2017, p. 178) argues, that understandings of youth sexual and reproductive health are "located within contextual healthcare inequities that fracture along multiple lines of differentiation". To achieve such a contextualised view in Aotearoa's sexual and reproductive health policy requires a more than the rights-based perspective alone and for this reason the dual prong, the justice-based perspective, is also necessary.

\section{The second prong: a justice-based perspective}

The Sexual and Reproductive Justice framework places "rights within a social framework" (Gilliam, Neustadt, \& Gordon, 2009, p. 243). It explicitly resists neoliberal discourses of individual rights and the marketplace of choices, highlighting how marginalized members of society are denied these. Using an intersectional lens, a Sexual and Reproductive Justice framework connects reproductive issues with the range of interwoven, contextual dynamics that shape youth sexual and reproductive health. These include: (i) unequal social relations (gendered, ethnic/racialised, classand location-based); (ii) structural and systemic barriers; and (iii) discriminatory socio-cultural discourses and practices (Ross, 2017). The policy focus then shifts toward marginalisation and power relations in particular locations, and away from individual young people's vulnerability and personal characteristics (Riele, 2006). 
To assist with this shift, "health justice and social determinants thinking could be helpful to reproductive justice causes" (Rebouché, 2017, p. 607). Such perspectives offer structural explanations for disparate sexual and reproductive health outcomes - such as those occurring along ethnic lines in Aotearoa-emphasising the significance of income, class, and power that human rights strategies often overlook. They connect the justice-based perspective to analyses of the political, social, and economic forces that shape young people's life opportunities. Such analyses illuminate the cumulative effects of the deep socio-economic inequalities underlying reproductive injustices (Rebouché, 2017). Sexual and reproductive health policy that clearly draws on health justice and social determinants perspectives to make sense of epidemiological data can help to avoid singling out and pathologizing certain groups of young people.

Incorporating a Sexual and Reproductive Justice framework into policy also requires moving beyond an exclusive focus on quantitative, epidemiological evidence. Sexual and Reproductive Justice insists on the centring of people's own stories in strategies to improve sexual and reproductive health (Ross, 2017). Researchers in Aotearoa have criticised sexual and reproductive health policy for its over-reliance on quantitative evidence that neglects youth voices and agency and produces an over-generalised view of youth sexual and reproductive health (e.g., Maibvisira, Conn, \& Nayar, 2015; Redstone \& Conn, 2011). They have argued for a more participatory and contextualized approach to policy-making that views young people as political agents with legitimate knowledge, rather than passive recipients of adult assistance (Redstone \& Conn, 2011), as our analysis highlighted. Sexual and reproductive health policy should also include qualitative research evidence that provides nuanced understandings of sexual and reproductive health issues and helps ensure that policy is applicable to those experiencing health inequities and that they do not bear an undue burden in the healthcare system (Rogers \& Kelly, 2011). Foregrounding young people's social realities and the contextual factors that sustain the uneven distribution of sexual and reproductive health difficulties (e.g., family violence, housing, immigration) would counter the 'othering' focus on certain individual youth in policy.

\section{Conclusion}

We have proposed the Sexual and Reproductive Justice framework as an alternative to the riskbased approach currently used in Aotearoa's Sexual and Reproductive Health Strategy. With its dual focus on rights and justice, this new perspective provides a two-pronged approach that can guard against the introduction of veiled morality, covert stigmatisation and marginalisation that we identified in the current policy framework. A revised policy founded upon Sexual and Reproductive Justice has the potential to address the Sexual and Reproductive Health Strategy's original positive intentions of reducing health inequities and improving the sexual and reproductive health outcomes of all youth in Aotearoa. Moreover, because this approach extends beyond the introduction of rights, to include contextual specificities, it holds promise for future sexual and reproductive health policymaking and planning in Aotearoa and beyond. 
Acknowledgements: The research for this article was financially supported by the Massey University Research Fund, grant numbers RM19392 and RM19334. Our thanks to Daygan Eagar and Ally Gibson for their helpful input on earlier drafts.

Ethical approval: This article does not contain any studies with human participants or animals performed by any of the authors.

\section{References}

Asian Communities for Reproductive Justice. (2005). A new vision for advancing our movement for reproductive health, reproductive rights and reproductive justice. Oakland: Forward Together (Asian Communities for Reproductive Justice). Retrieved from https://forwardtogether.org/wp-content/uploads/2017/12/ACRJ-A-New-Vision.pdf

Breheny, M., \& Stephens, C. (2010). Youth or disadvantage? The construction of teenage mothers in medical journals. Culture, Health \& Sexuality, 12(3), 307-322. https://doi.org/10.1080/13691050903513234

Brown, S. (2016). 'They're not this kind of thing that you think they are': Patterns, trends and policy. In Teenage Pregnancy, Parenting and Intergenerational Relations, (p. 259). https://doi.org/10.1057/978-1-137-49539-6

Brown, S., Shoveller, J., Chabot, C., \& LaMontagne, A. D. (2013). Risk, resistance and the neoliberal agenda: young people, health and well-being in the UK, Canada and Australia. Health, Risk and Society, 15(4), 333-346. https://doi.org/10.1080/13698575.2013.796346

Clark, T. C., Crengle, S., Sheridan, J., Rowe, D., \& Robinson, E. (2014). Factors associated with consistent contraception and condom use among Māori secondary school students in New Zealand. Journal of Paediatrics and Child Health, 50(4), 258-265. https://doi.org/10.1111/jpc.12450

Clark, T. C., Lucassen, M. F. G., Fleming, T., Peiris-John, R., Ikihele, A., Teevale, T., ... Crengle, S. (2016). Changes in the sexual health behaviours of New Zealand secondary school students, 2001-2012: Findings from a national survey series. Australian and New Zealand Journal of Public Health, 40(4), 329-336. https://doi.org/10.1111/17536405.12543

Durie, M. (2003). Nga Kahui Pou: Launching Maori Futures. Auckland, New Zealand: Huia Publishers.

Edwards, O. W., Mumford, V. E., \& Serra-Roldan, R. (2007). A positive youth development model for students considered at-risk. School Psychology International, 28(1), 29-45.

Family Planning New Zealand. (2017). Sexual and reproductive health and rights in New Zealand: Briefing to incoming members of parliament. Wellington, New Zealand: Family Planning New Zealand.

Gilliam, M. L., Neustadt, A., \& Gordon, R. (2009). A call to incorporate a reproductive justice agenda into reproductive health clinical practice and policy. Contraception, 79(4), 243-6. https://doi.org/10.1016/j.contraception.2008.12.004 
Gorur, R. (2015). Vulnerability: Construct, complexity and consequences. In K. te Riele \& R. Gorur (Eds.), Interrogating conceptions of "vulnerable youth" in theory, policy and practice (pp. 3-1). Rotterdam, Boston, Taipei: Sense Publishers.

Green, A. (2011). A discursive analysis of Māori in sexual and reproductive health policy. (Masters of Māori and Pacific Development at the University of Waikato, Hamilton, New Zealand). University of Waikato, Hamilton.

Green, A., Tipene, J., \& Davis, K. (2016). Mana tangata whenua: National Guidelines for Sexual and Reproductive Health Promotion with Māori. Hamilton, New Zealand. Retrieved from http://tewhariki.org.nz

Horrocks, C., \& Johnson, S. (2014). A Socially Situated Approach to Inform Ways to Improve Health and Wellbeing. From Health Behaviours to Health Practices: Critical Perspectives, 36(2), 19-30. https://doi.org/10.1002/9781118898345.ch3

Jackson, S. (2004). Identifying Future Research Needs for the Promotion of Young People's Sexual Health in New Zealand. Social Policy Journal of New Zealand, (21), 123-136.

Retrieved from http://search.proquest.com/docview/61793078?accountid=15172\%5Cnhttp://sfx.library.yale .edu/sfx_local?url_ver=Z39.88-

2004\&rft_val_fmt=info:ofi/fmt:kev:mtx:journal\&genre=article\&sid=ProQ:ProQ: socabsshel $1 \&$ atitle=Identifying+Future+Research+Needs+for+the+Prom

Kelly, P. (2001). Youth at Risk: Processes of individualisation and responsibilisation in the risk society Youth at Risk : processes of individualisation and responsibilisation in the risk society. Discourse: Studies in the Cultural Politics of Education, 22(1), 37-41. https://doi.org/10.1080/0159630012003973

Kemshall, H. (2008). Risks, Rights and Justice: Understanding and Responding to Youth Risk. Youth Justice, 8(1), 21-37. https://doi.org/10.1177/1473225407087040

Lowe, P. (2016). Reproductive health and maternal sacrifice: Women, choice and responsibility. Birmingham, United Kingdom: Palgrave Macmillan. https://doi.org/10.1057/978-1-13747293-9

Lupton, D. (2012). "Precious cargo": foetal subjects, risk and reproductive citizenship. Critical Public Health, 223, 329-340. https://doi.org/10.1080/09581596.2012.657612

Lupton, D. (2013). Risk (2nd ed.). Oxford, United Kingdom: Routledge.

Macleod, C. (2011). Constructing a threat of degeneration: "Adolescent” pregnancy and abortion. London and New York: Routledge.

Macleod, C. (2017). 'Adolescent' sexual and reproductive health: Controversies, rights And justice. In A. L. Cherry, L. Baltag, \& M. E. Dillon (Eds.), An International Handbook on Adolescent Health and Development: The Public Health Response (pp. 169-181). New York: Springer.

Macvarish, J. (2010). The effect of "risk-thinking" on the contemporary construction of teenage motherhood. Health, Risk and Society, 12(4), 313-322. https://doi.org/10.1080/13698571003789724 
Maibvisira, C., Conn, C., \& Nayar, S. (2015). Diverse youth voices and New Zealand public policy. Vulnerable Children and Youth Studies, 10(1), 36-40. https://doi.org/http://dx.doi.org/10.1080/17450128.2014.963774

McCulloch, A., \& Weatherall, A. (2017). The fragility of de facto abortion on demand in New Zealand Aotearoa. Feminism \& Psychology, 27(1), 92-100. https://doi.org/10.1177/0959353516679432

McGregor, S. (2001). Neoliberalism and health care. International Journal of Consumer Studies, 25(2), 82-89. https://doi.org/10.1111/j.1470-6431.2001.00183.x

Miller, D. (2016). Equity in sexual and reproductive health - an ongoing challenge. Journal of Primary Health Care, 8(1), 3-4. https://doi.org/10.1071/HCv8n1_ED2

Ministry of Health. (2001). Sexual and Reproductive Health Strategy Phase One. Wellington, New Zealand. Retrieved from http://www.moh.govt.nz

Ministry of Health. (2002). Youth Health: A Guide to Action. Wellington. Retrieved from www.moh.govt.govt.nz

Ministry of Health. (2003). Sexual and reproductive health: A resource book for New Zealand. Wellington, New Zealand. Retrieved from http://www.moh.govt.nz

Ministry of Youth Affairs. (2002). Youth Development Strategy Aotearoa. Wellington, New Zealand. Retrieved from www.youthaffairs.govt.nz

Monterro, K., \& Kelly, P. (2016). Young People and the Aesthetics of Health Promotion : Beyond Reason, Rationality and Risk. London and New York: Routledge.

Morison, T., Herbert, S. \& Eagar, D. (2018). Rethinking 'risk' in sexual and reproductive health policy: Implications for marginalised youth. Palmerston North, New Zealand: Massey University. Available at https://www.massey.ac.nz/massey/learning/departments/school-ofpsychology/research/research-clusters/chasp/research-findings/research-findings_home.cfm

Morison, T., \& Macleod, C. (2015). Men's pathways to parenthood: Silence and heterosexula gendered norms. Cape Town: HSRC Press.

New Zealand First. (2000). Better economics but socially 'racial apartheid.' Scoop Independent News. Retrieved from http://www.scoop.co.nz/stories/PA0006/S00307.htm

New Zealand Sexual Health Society. (2011). Request for Action on the Development of a National Sexual Health Strategy and Action Plan. Retrieved from https://nzshs.org/news/policy-submissions/188-development-of-a-sexual-health-strategyand-action-plan/file

Peterson, A., \& Lupton, D. (2000). The new public health: Health and self in the age of risk. London: SAGE Publications.

Pihama, L. (2011). Overview of Māori Teen Pregnancy. Wellington. Retrieved from http://www.superu.govt.nz/sites/default/files/maori-teen-pregnancy.pdf

Prince, R., Kearns, R., \& Craig, D. (2006). Governmentality, discourse and space in the New Zealand health care system, 1991-2003. Health and Place, 12(3), 253-266. https://doi.org/10.1016/j.healthplace.2004.09.003

Rebouché, R. (2017). Reproducing Rights: The Intersection of Reproductive Justice and Human 
Rights. UC Irvine Law Review, 7(579), 582-610.

Redstone, N., \& Conn, C. (2011). Sexual Health and "Asian" and "Pacific" Young People from Auckland Diasporas (No. 5). CDS Working Paper Series. Auckland, New Zealand.

Reynolds, J., Wetherell, M., \& Taylor, S. (2007). Choice and chance: negotiating agency in narratives of singleness. The Sociological Review, 55(2), 331-351.

https://doi.org/10.1111/j.1467-954X.2007.00708.x

Riele, K. Te. (2006). Youth "at risk": Further marginalizing the marginalized? Journal of Education Policy, 21(2), 129-145. https://doi.org/10.1080/02680930500499968

Rogers, J., \& Kelly, U. A. (2011). Feminist intersectionality: Bringing social justice to health disparities research. Nursing Ethics, 18(3), 397-407.

Ross, L. J. (2017). Conceptualising reproductive justice theory: A manifesto for activism. In Radical reproductive justice: Foundation, theory, practice, critique. New York, NY, US: Feminist Press.

Ross, L. J. (2018). Reproductive Justice as Intersectional Feminist Activism. Souls, 19(3), 286314. https://doi.org/10.1080/10999949.2017.1389634

Ross, L. J., \& Solinger, R. (2017). Reproductive justice: An introduction. Oakland: California University Press.

Rothstein, H. (2006). The institutional origins of risk: A new agenda for risk research. Health, Risk \& Society, 8(3), 215-221.

Shoveller, J. A., \& Johnson, J. L. (2006). Risky groups, risky behaviour, and risky persons: Dominating discourses on youth sexual health. Critical Public Health, 16(1), 47-60. https://doi.org/10.1080/09581590600680621

Sistersong Women of Color Reproductive Health Collective and the Pro-Choice Public Education Project. (2007). Reproductive Justice Briefing Book: A Primer on Reproductive Justice and Social Change. Retrieved from https://tinyurl.com/y6vmceht

Social Policy and Evaluation Research Unit. (2015). Teen births : Current trends in New Zealand. Wellington, New Zealand. Retrieved from www.superu.govt.nz

Tairawhiti District Health. (2008). Sexual Health Over Tairawhiti Strategy. te Riele, K. (2006). Youth "at risk": Further marginalizing the marginalized? Journal of Education Policy, 21(2), 129-145. https://doi.org/10.1080/02680930500499968

te Riele, K. (2015). Conundrums for youth policy and practice. In K. te Riele \& R. Gorur (Eds.), Interrogating conceptions of "vulnerable youth" in theory, policy and practice (Volume 2, pp. 17-32). Rotterdam, Boston, Taipei: Sense Publishers.

Terry, G., Braun, V., \& Farvid, P. (2012). Structural impediments to sexual health in New Zealand: Key informant perspectives. Sexuality Research and Social Policy, 9, 317-326. https://doi.org/10.1007/s13178-012-0089-y

Ware, F. J. R. (2014). Whanau kopepe: A culturally appropriate and family focused approach to support for young Maori (Indigenous) parents. Journal of Indigenous Social Development, 3(2), 1-20. Retrieved from http://www.hawaii.edu/sswork/jisd\%5Cnhttp://scholarspace.manoa.hawaii.edu/ 
Ware, F. J. R., Breheny, M., \& Forster, M. (2016). The politics of government "support” in Aotearoa/New Zealand: Reinforcing and reproducing the poor citizenship of young Māori parents. Critical Social Policy, 1-21. https://doi.org/10.1177/0261018316672111

Women's Health Action. (n.d.). Improving the health of women in Aotearoa New Zealand (Universal Periodic Review Submission on the Right to Health). Auckland, New Zealand. Youthline Auckland Charitable Trust. (2011). Adolescent and Youth Sexual and Reproductive Health. Auckland, New Zealand. Retrieved from https://www.youthline.co.nz/assets/Uploads/PDFs/Youthline-Positional-Paper-Sexual-andreproductive-health-2011.pdf

\footnotetext{
${ }^{i}$ Note, however, that statistics do not distinguish between teenage pregnancies that are planned and/or wanted and those that are not. Instead teenage pregnancy is problematised in toto, with concerns voiced in policy and elsewhere about young maternal age and assumed poor social, economic, and health outcomes for these women, their children, and wider society (Morison, Herbert, \& Eagar (2018) and see also Breheny and Stephens (2010) and Macleod (2011) on this issue).
} 
Rethinking 'Risk' in Sexual and

Reproductive Health Policy: the Value of the Reproductive Justice Framework

Morison, $\mathrm{T}$

2019-12

22/04/2023 - Downloaded from MASSEY RESEARCH ONLINE 